\title{
STATUS REPORT FOR MOISTURE EFFECTS ON COMPACTION OF FIBERBOARD IN A 9975 SHIPPING PACKAGE (U)
}

\author{
T. M. Stefek \\ W. L. Daugherty \\ E. G. Estochen \\ Savannah River National Laboratory \\ Materials Science \& Technology
}

Publication Date: June 2011

Savannah River Nuclear Solutions

Savannah River Site

Aiken, SC 29808

This document was prepared in conjunction with work accomplished under

Contract No. DE-AC09-08SR22470 with the U.S. Department of Energy. 
SRNL-STI-2011-00218

\section{DISCLAIMER}

This work was prepared under an agreement with and funded by the U.S. Government. Neither the U. S. Government or its employees, nor any of its contractors, subcontractors or their employees, makes any express or implied: 1 . warranty or assumes any legal liability for the accuracy, completeness, or for the use or results of such use of any information, product, or process disclosed; or 2. representation that such use or results of such use would not infringe privately owned rights; or 3. endorsement or recommendation of any specifically identified commercial product, process, or service. Any views and opinions of authors expressed in this work do not necessarily state or reflect those of the United States Government, or its contractors, or subcontractors. 
Status Report for Moisture Effects on Compaction of Fiberboard in a 9975 Shipping Package (U)

\section{APPROVALS:}

T. M. Stefek

Date Author, Materials Science and Technology

W. L. Daugherty Date

Author, Materials Science and Technology

E. G. Estochen

Date

Author, Materials Science and Technology

K. A. Dunn Date

$\mathrm{Pu}$ Surveillance Program Lead, Materials Science and Technology

G. T. Chandler Manager, Materials App \& Process Tech

Date

E. R. Hackney

Date

NMM Engineering

\section{REVIEWS:}

D. R. Leduc Date 


\section{Revision Log}

$\begin{array}{lll}\text { Document No. } & \text { SRNL-STI-2011-00218 Rev. No. } 0\end{array}$

Document Title Status Report for Moisture Effects on Compaction of Fiberboard in a 9975 Shipping Package (U)

Rev. \# Page \# Description of Revision Date

$\begin{array}{lll}0 & \text { all Original document } 6 / 23 / 2011\end{array}$ 


\section{SUMMARY}

Compaction of lower layers in the fiberboard overpack has been observed in 9975 packages that contain elevated moisture. Lab testing has resulted in a better understanding of the relationship between the fiberboard moisture level and compaction of the lower fiberboard assembly, and the behavior of the fiberboard during transport. In laboratory tests, higher moisture content has been shown to correspond to higher total compaction of fiberboard material, greater rate of compaction, and continued compaction over a longer period of time. In addition, laboratory tests have shown that the application of a dynamic load results in higher fiberboard compaction. The test conditions and sample geometric/loading configurations were chosen to simulate the regulatory requirements for 9975 package input dynamic loading. Dynamic testing was conducted over a period of six months to acquire immediate and cumulative changes in geometric data for various moisture levels. Currently, one sample set has undergone a complete dynamic test regimen, while testing of another set is still in-progress. The dynamic input, data acquisition, test effects on sample dynamic parameters, and interim results from this test program are summarized and compared to regulatory specifications for dynamic loading. This will provide a basis from which to evaluate the impact of moisture and fiberboard compaction on the safety basis for transportation (Safety Analysis Report for Packaging) and storage (facility Documented Safety Analysis) at the Savannah River Site (SRS).

\section{BACKGROUND}

This is an interim status report of Task 1 tests carried out per Task Technical and Quality Assurance Plan SRNS-TR-2010-00044, “TTQAP For Testing of Moisture Effects on Model 9975 Package [1]", which is part of the comprehensive 9975 package surveillance program [2]. Task 1 tests were developed to determine the impact of fiberboard moisture level on compaction under load.

Experience with fiberboard compaction includes the identification of several packages in which the axial gap has increased and exceeded the response threshold of 1 inch. This observation was generally accompanied by elevated moisture levels in the bottom fiberboard layers and compaction of those layers. Elevated moisture might accumulate within the fiberboard due to the introduction of moisture to the package, or by the concentration of existing moisture into local regions through migration under thermal gradient. The impact of elevated moisture on fiberboard properties and the response of the package to changing moisture conditions has been described [3]. Over time, elevated moisture levels will accelerate the degradation rates of the fiberboard properties $[4,5]$.

\section{EXPERIMENTAL APPROACH}

Laboratory tests have been performed to compare the response of fiberboard to transient loadings on different time scales using three test methods (Table 1).

- Short-term tests measured the fiberboard response under load within a single, very long load cycle.

- Standard compression tests subjected the samples to a single half-cycle loading event. 
- Dynamic tests have subjected the samples to a dynamic load of varying frequency and amplitude, such as might occur during handling and transport.

While the short term and compression tests offer a simpler look at the basic response of the fiberboard under a single dynamic cycle, the dynamic tests better simulate the conditions a package might experience in service. Preliminary results for each test method were presented in a paper at the Institute for Nuclear Materials Management (INMM) conference in 2010 [6].

Table 1. Test Matrix

\begin{tabular}{|c|c|c|c|}
\hline \multirow[b]{2}{*}{$\begin{array}{l}\text { Sample } \\
\text { Number }\end{array}$} & \multicolumn{3}{|c|}{ Target Test Conditions } \\
\hline & Stress (psi) & \%WME & $\begin{array}{c}\text { Weight } \\
\text { (Ibs) }\end{array}$ \\
\hline \multicolumn{4}{|c|}{ Short Term Tests } \\
\hline S1 & 6.8 & 10 & $50 / 100$ \\
\hline S2 & 5.4 & 20 & $40 / 80$ \\
\hline S3 & 5.4 & 30 & $40 / 80$ \\
\hline S4 & 6.8 & 15 & $50 / 100$ \\
\hline S5 & 5.4 & 25 & $40 / 80$ \\
\hline S6 & 5.4 & 35 & $40 / 80$ \\
\hline \multicolumn{4}{|c|}{ Compression Tests } \\
\hline LD2 & $\mathrm{n} / \mathrm{a}$ & $7.5-12.5$ & $\mathrm{n} / \mathrm{a}$ \\
\hline New & $\mathrm{n} / \mathrm{a}$ & $6.7-12.0$ & $\mathrm{n} / \mathrm{a}$ \\
\hline 02028 & $\mathrm{n} / \mathrm{a}$ & 10.9 & $\mathrm{n} / \mathrm{a}$ \\
\hline \multicolumn{4}{|c|}{ Dynamic Tests } \\
\hline $50 C$ & 3.4 & 10 & 50 \\
\hline $40 E$ & 2.7 & 20 & 40 \\
\hline $40 \mathrm{~F}$ & 2.7 & 30 & 40 \\
\hline D-50-6 & 3.4 & 6 & 50 \\
\hline D-40-25 & 2.7 & 25 & 40 \\
\hline D-40-35 & 2.7 & 35 & 40 \\
\hline \multicolumn{4}{|c|}{ Dynamic Tests (control samples) } \\
\hline $50 \mathrm{~A}$ & 3.4 & 10 & 50 \\
\hline $40 \mathrm{~A}$ & 2.7 & 20 & 40 \\
\hline $40 C$ & 2.7 & 30 & 40 \\
\hline S-50-6 & 3.4 & 6 & 50 \\
\hline S-50-10 & 3.4 & 10 & 50 \\
\hline S-40-25 & 2.7 & 25 & 40 \\
\hline S-40-35 & 2.7 & 35 & 40 \\
\hline
\end{tabular}

The bottom of the 9975 outer drum is dished (Figure 1), and the fiberboard overpack is fabricated with a flat bottom. Therefore, as the load on the fiberboard increases, the bottom layer will increasingly compress from the outer edge inward as it conforms to the drum bottom. The lead shield (and the containment vessels and payload contained within) sit on an aluminum 
bearing plate embedded within the lower fiberboard assembly. The bearing plate, shield, containment vessels and a typical loaded 3013 container place a load of approximately 263 pounds on the fiberboard.

Typically, a ring of compressed fiberboard will form around the outer edge of the bottom surface approximately $1 \frac{1}{2}-2$ inches wide. As the bottom layer(s) compress further (due to increased loading or reduced fiberboard strength), this ring will widen until the entire fiberboard bottom surface is in contact with the drum bottom. This has been observed in packages with elevated moisture content, and is illustrated in Figure 1. With the limited contact area, the peak stress in the bottom fiberboard layers is typically no greater than 3.4 psi. As the compressed region widens, the peak stress decreases to $2.7 \mathrm{psi}$, which is the stress immediately under the bearing plate.
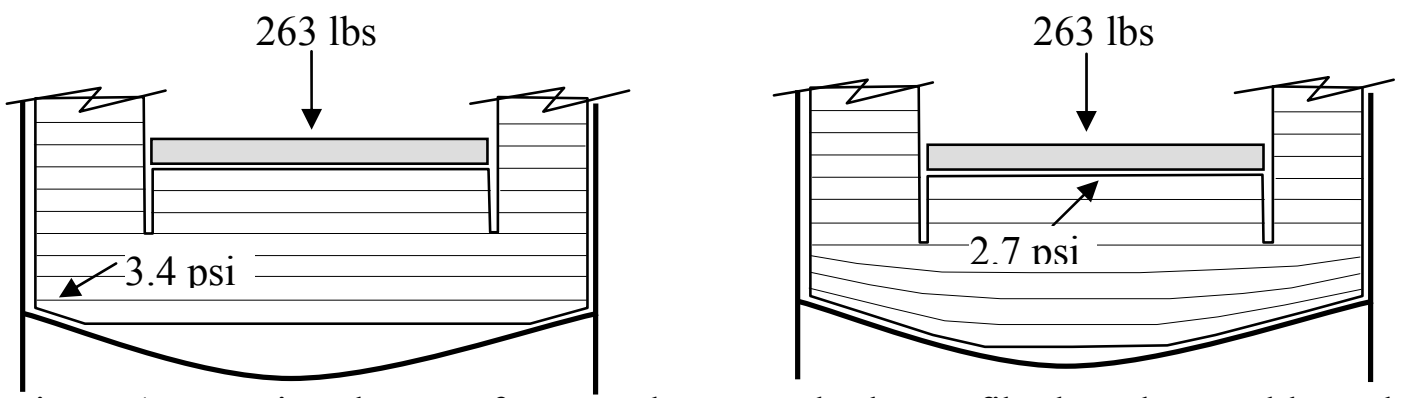

Figure 1. Varying degree of contact between the lower fiberboard assembly and drum bottom. As the contact area increases, the peak fiberboard stress will decrease to that immediately under the bearing plate. NOTE: Degree of curvature exaggerated for visual effect.

\section{Short-Term Testing}

Samples of the same size with moisture content between approximately 10 to $35 \% \mathrm{WME}$ (wood moisture equivalent) ${ }^{1}$ had an initial load applied. The samples were monitored until the sample height stabilized, at which time the load on each sample was doubled, representing one very slow cycle of dynamic loading. The loads were then removed and the rebound was measured. The height of each sample is measured by extending a caliper through each of 4 holes in the plate on top of the sample. By averaging these 4 measurements, variation from tipping if the sample compresses non-uniformly is eliminated. The thickness of the plate is subtracted from the measurement to get the actual sample height. In the short-term tests, the initial loading cycle was indicative of the response of the lower layers of the fiberboard assembly when the package is first assembled. Similarly, the second loading cycle approximated the response during some period of handling or transport, and removal of the higher load represents an end to the dynamic activity as the package sits in storage.

Samples approximately $4 \times 4 \times 2$ inches in size were removed from a single fiberboard assembly (Package 9975-02028). Each sample has different moisture content, ranging from approximately

$1 \%$ WME represents the electrical resistivity measured by a wood moisture meter. For cane fiberboard, it relates to moisture content by: wt $\%$ moisture $\cong 0.67 * \% \mathrm{WME}+2.6$, over a range up to $\sim 40 \% \mathrm{WME}$. 
10 to $35 \%$ WME. Each sample is contained within a plastic bag to help maintain a constant moisture level throughout testing. For nominal moisture samples (10 - 15\%WME), the target stress level is approximately 3.4 psi. For higher moisture content ( $\geq 20 \% \mathrm{WME}$ ), the target stress level is approximately 2.7 psi. These stress levels are achieved by placing a weight on each sample (see Figure 2). The initial load is placed on each sample, and the sample height allowed to stabilize. The degree of compression is measured repeatedly until it appears stable (typically up to several days). The load on each sample is then doubled (to 5.4 or 6.8 psi) to simulate one very slow cycle of dynamic loading. Each load is then removed in steps as the material rebound is measured.

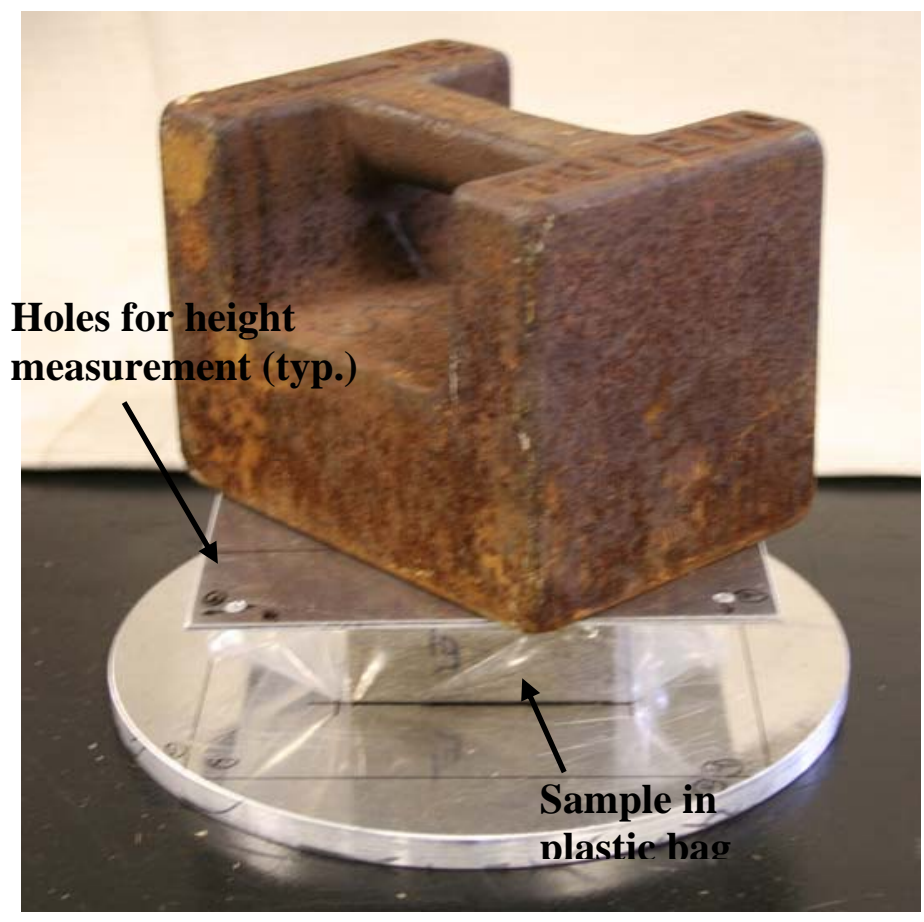

Figure 2. Typical test setup for short-term test sample. Sample height is measured in-situ by extending calipers through each of 4 holes in the upper plate.

\section{Compression Testing}

A set of 8 compression samples ( $2 \times 2 \times 2$ inch) were tested with the load applied perpendicular to the fiberboard layers, with a crosshead speed of 1.9 inch/minute. The sample results were taken from several different package assemblies which were tested previously [4, 5]. Packageto-package variability was observed, and data from two packages (LD2 and New) are included in this status report. These two packages had moisture content ranging from 6.7 to $12.5 \% \mathrm{WME}$, which is typical of the seasonal variation for material in equilibrium with the ambient humidity. A ninth compression sample was taken from the same package as the short-term and dynamic test samples (Package 9975-02028). This sample was tested at a moisture content of 10.9 $\% \mathrm{WME}$ to provide direct comparison to results from the other test methods, without package-topackage variation.

The compression test behavior of fiberboard has been described previously [5, 7]. While a compression test typically extends to high strain levels, the data of current interest is the compression behavior at very low strains, corresponding to stress levels of $<10 \mathrm{psi}$. 


\section{Dynamic Testing}

Fiberboard samples have been placed under load similar to that seen in service by the lower layers in a 9975 package, and compaction values are being tracked over time. Some samples are subjected to periodic dynamic loading that simulates potential transport conditions. The remaining samples experience a static load only. Sample height and moisture content are recorded weekly. Sample height is measured in 4 locations as described above for short-term testing.

Samples approximately $4 \times 4 \times 2$ inches in size were removed from the same fiberboard assembly used for short-term tests (Package 9975-02028). Two sets of samples were prepared for testing. The first set consists of three samples that contain moisture levels of approximately 10, 20 and $30 \% \mathrm{WME}$. The second set consists of three samples that contain moisture levels of approximately 6, 25, and $35 \%$ WME. Each sample is enclosed within a box to help maintain a constant moisture level throughout testing. The target stress level for nominal moisture samples $(6-15 \% \mathrm{WME})$ is approximately 3.4 psi. For higher moisture content $(\geq 20 \% \mathrm{WME})$, the target stress level is approximately $2.7 \mathrm{psi}$. These stress levels are achieved by placing a weight on each sample. The dynamic samples are placed on a cart, and the dynamic loadings result as the cart is moved over a rough surface (metal plates mounted to an expanded metal sheet) according to a set pattern (see Figure 3). The wheels are 5 inches in diameter and are made of plastic with a solid rubber tire. The degree of sample compression is measured before and after each transport cycle simulation. The dynamic load, transmitted to the samples by rolling the cart over the rough surface, is recorded using accelerometers. One accelerometer (PCB model \#353B33, Sensitivity $=0.104 \mathrm{Volt} / \mathrm{g}$ ) is screw mounted to the top of the sample enclosure, and a second accelerometer (Kistler model \#8630B5, Sensitivity=0.984 Volt/g) is mounted with wax adhesive to the floor of the cart proximate to a corner.

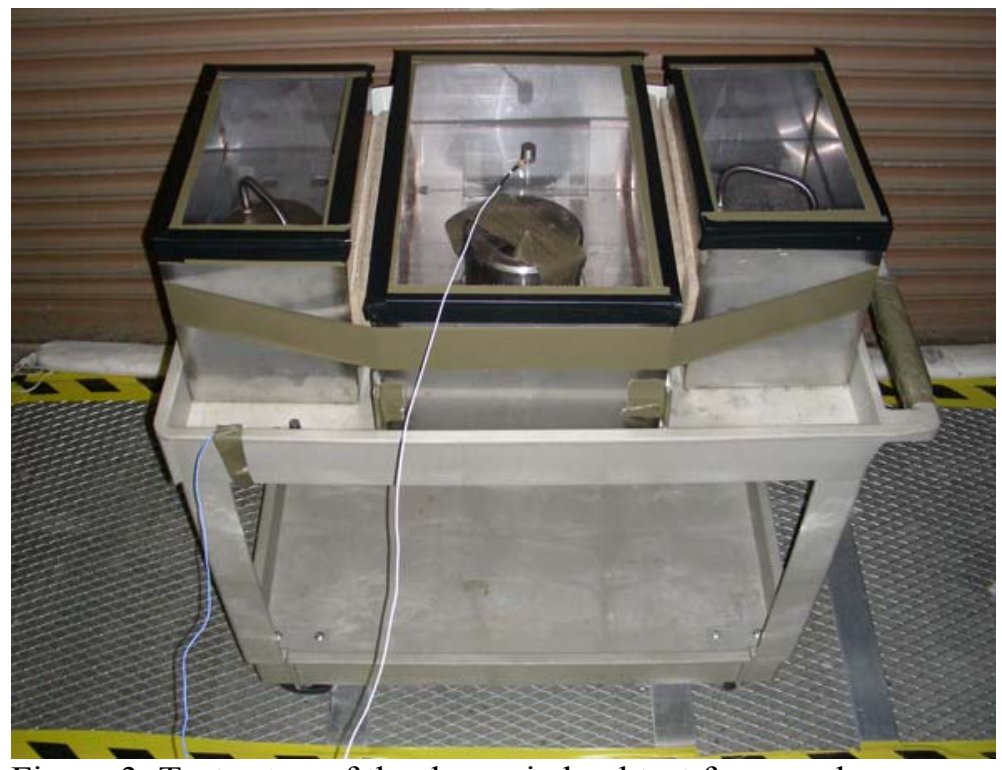

Figure 3. Test setup of the dynamic load test for samples

(a) Sample boxes on cart

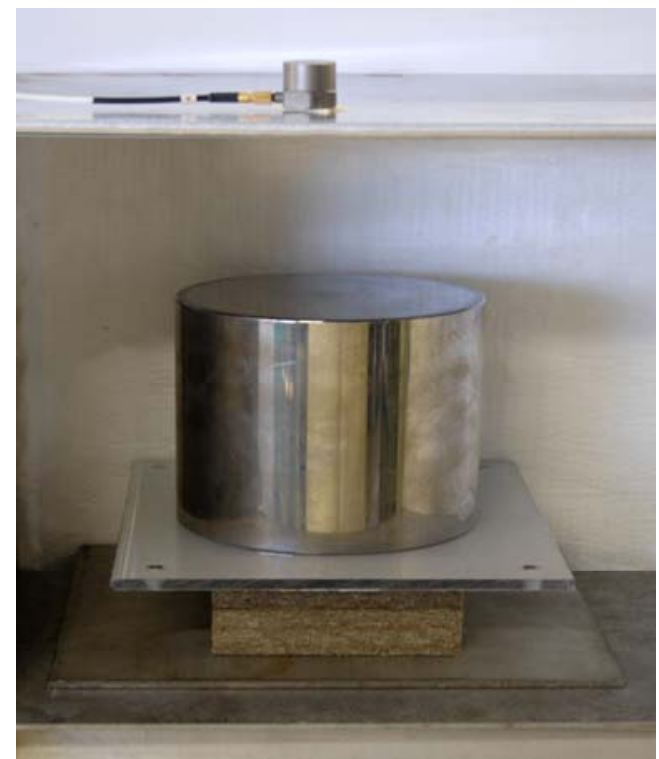

(b) Arrangement within sample boxes 


\section{RESULTS}

\section{Short-Term Testing}

The short-term samples were maintained under load for varying periods, depending on the sample response. The change in sample height during loading and unloading for samples with $10,15,20,25,30$ and $35 \% \mathrm{WME}$ is shown in Figure 4.

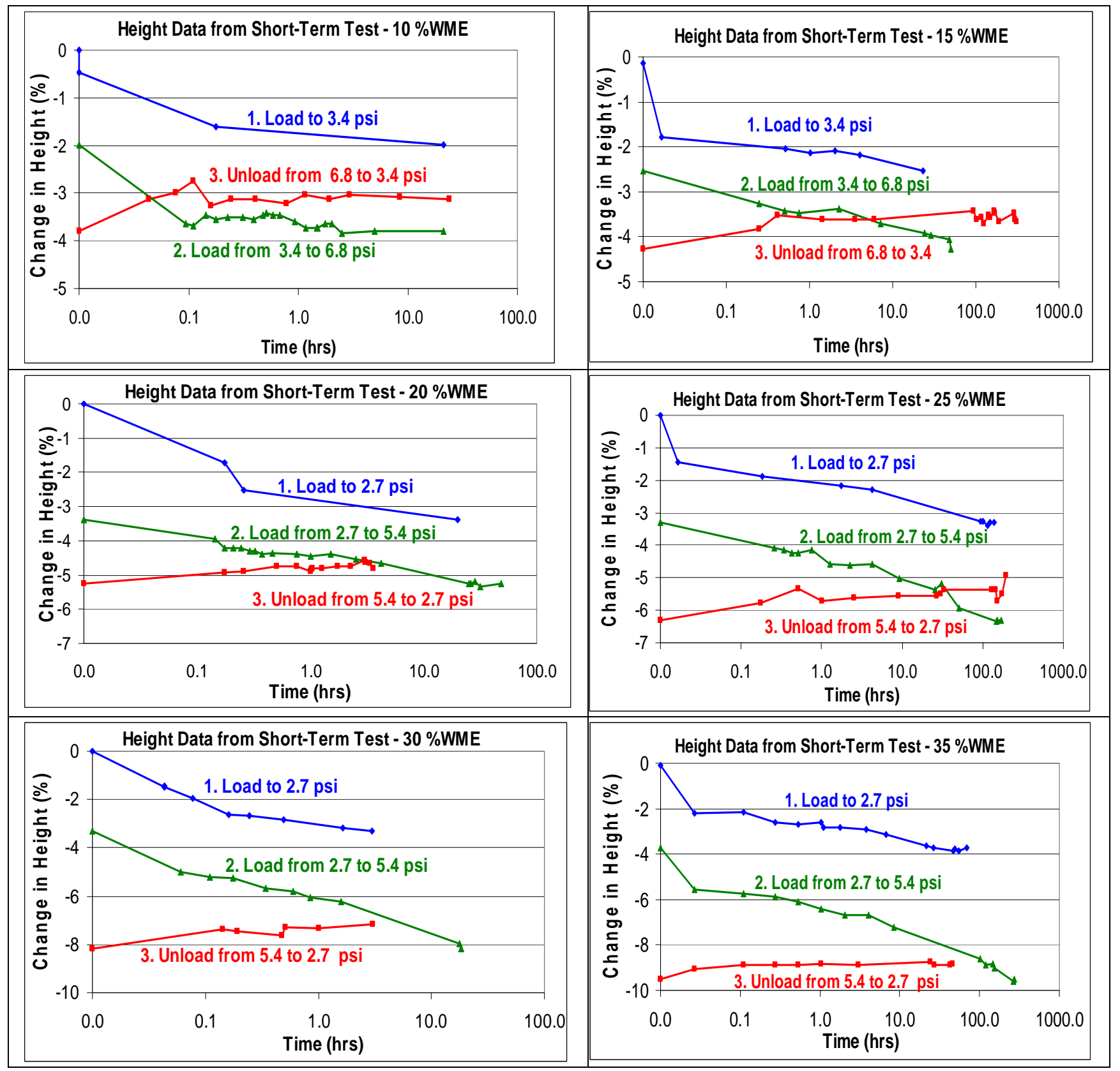

Figure 4. Change in sample height during short-term testing 


\section{Compression Testing}

A range of stress-strain response is seen based on the source package and moisture content (Figure 5). This figure shows package-to-package variation in addition to variation from moisture content. The area of interest in the compression test curve is at very low stress levels $(\sim 3-5$ psi). However, the stress-strain curve is not always consistent in this range due to minor sample misalignment, machine slack, etc. Therefore, the behavior at this stress level is determined by measuring the slope of the stress-strain curve at slightly higher stress levels $(\sim 20$ $30 \mathrm{psi}$ ) and extrapolating to lower stresses. This is illustrated in Figure 5 for source package LD2. The slope for each sample is summarized in Table 2 along with the extrapolated degree of compression at stresses of 3.4 and 6.8 psi.

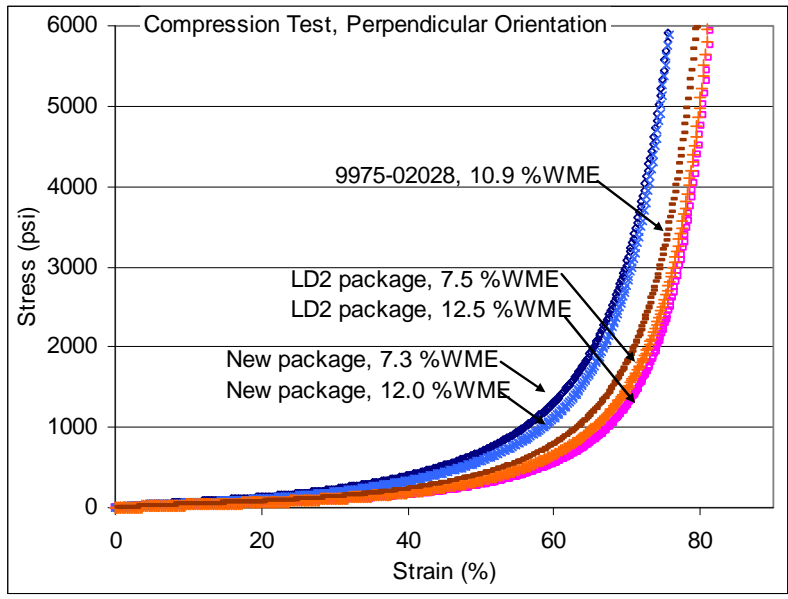

Figure 5a. Stress strain curves for fiberboard from two packages at two moisture levels, compared to package 9975-02028.

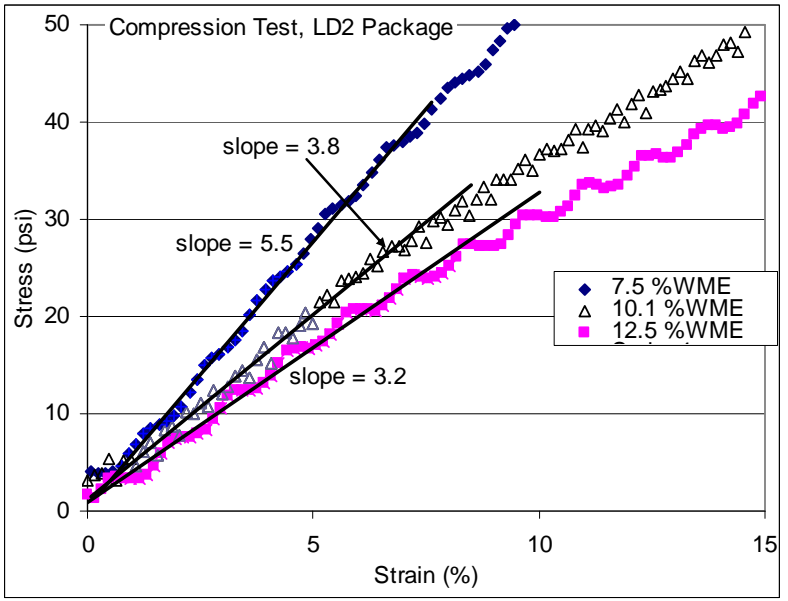

Figure $5 \mathrm{~b}$. Low stress portion of compression test curves for LD2 package samples, with slope fit to lower section of the curve.

Table 2. Summary of slopes from low stress portion of compression test curves, with extrapolated estimates of compression (percentage loss of original height) at select stress levels.

\begin{tabular}{|c|c|c|}
\hline Package LD2 & Package New & 9975-02028 \\
\hline \multicolumn{3}{|c|}{ Slope of compression curve @ moisture level } \\
\hline & 7.5 psi/\%@6.7\%WME & \\
\hline $5.5 \mathrm{psi} / \% @ 7.5 \% \mathrm{WME}$ & 8.7 psi/\%@7.3\%WME & \\
\hline 3.8 psi/\%@10.1\%WME & & 4.9 psi/\%@10.9 WME \\
\hline 3.2 psi/\%@12.5\%WME & 7.5 psi/\%@12.0\%WME & \\
\hline \multicolumn{3}{|c|}{ Estimated sample compression at 3.4 psi } \\
\hline \multirow[t]{2}{*}{$0.62 \% @ 7.5 \% \mathrm{WME}$} & 0.39\%@7.3\%WME & \\
\hline & & 0.69\%@10.9\%WME \\
\hline $1.06 \% @ 12.5 \% \mathrm{WME}$ & $0.45 \% @ 12.0 \% \mathrm{WME}$ & \\
\hline \multicolumn{3}{|c|}{ Estimated sample compression at 6.8 psi } \\
\hline \multirow[t]{2}{*}{ 1.24\%@7.5\%WME } & $0.78 \% @ 7.3 \% \mathrm{WME}$ & \\
\hline & & 1.39\%@10.9\%WME \\
\hline $2.12 \% @ 12.5 \% \mathrm{WME}$ & 0.91\%@12.0\%WME & \\
\hline
\end{tabular}




\section{Dynamic Testing}

The samples are subjected to a dynamic transport simulation cycle immediately after they are placed under nominal load, and then once per week for a period of approximately 6 months (relatively little change was observed in the first set after 19 weeks). Following dynamic testing of the first set, a second set of dynamic samples began testing and has currently accumulated 15 weeks exposure. Sample heights are measured before and after each cycle of dynamic excitation. Heights of the control samples, which experience a static load only, are measured weekly as well. The relative change in height for each of these samples is shown in Figure 6. The 6 and $10 \%$ WME samples were loaded to 3.4 psi, while the other samples were loaded to 2.7 psi.

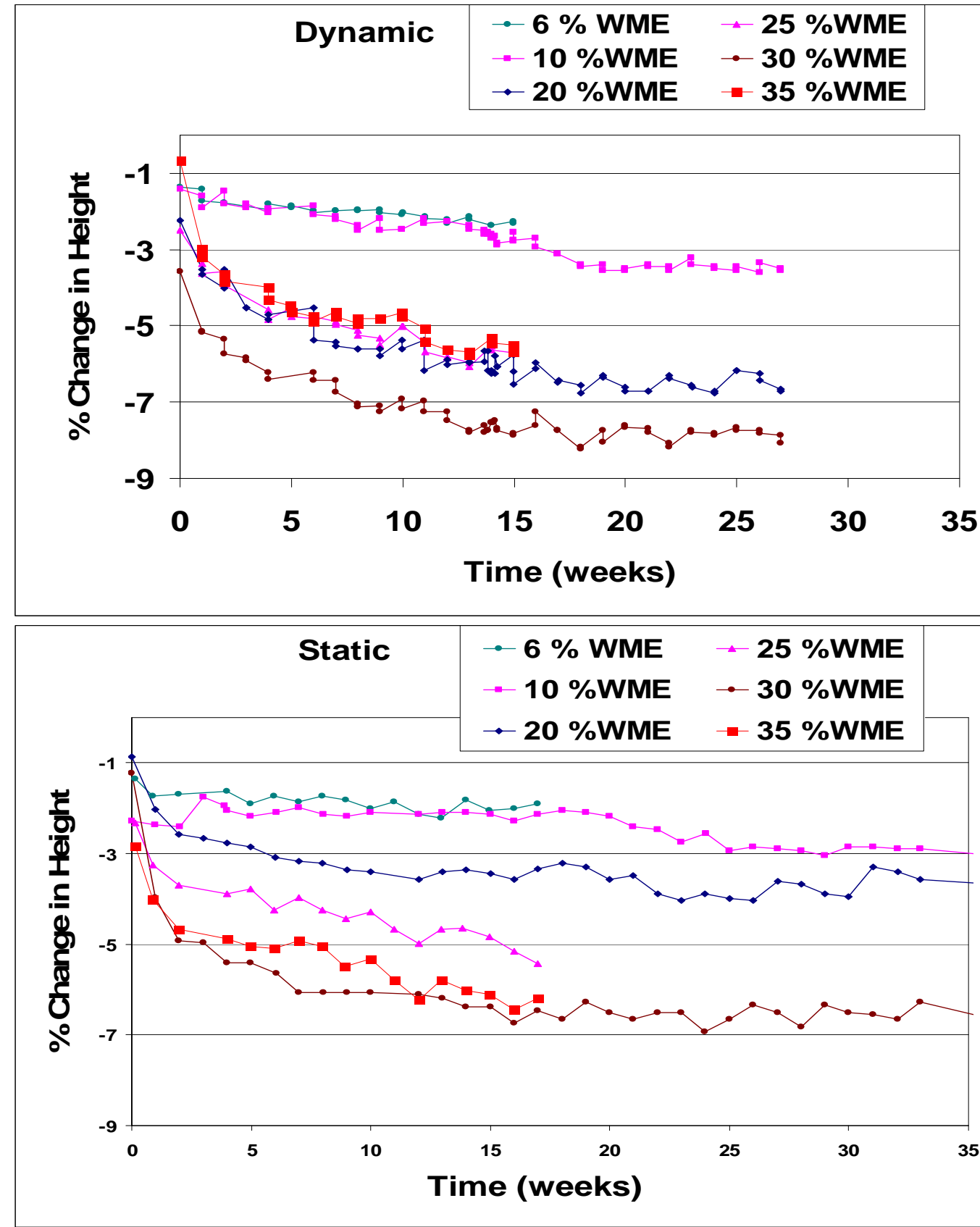

Figure 6a.

Relative change in height (strain) under load for dynamic test samples.

Figure $6 b$.

Relative change in height (strain) under load for static (control) test samples. 
During the transport simulation cycle, acceleration measurements were recorded in 2 second intervals for conversion to spectral data in a frequency range of 0-200 Hertz. The dynamic data were captured using a Fast Fourier Transform (FFT) analyzer, in a continuous capture mode, to collect all data while the cart was rolled over the rough surface. The FFT analyzer was configured with measurement parameters that included Peak Continuous capture mode (i.e., the peak value measured at each frequency is retained and updated for each increment of the overall measurement), and Hanning Window data smoothing to improve measurement accuracy by minimizing FFT leakage resulting from waveform time-to-frequency domain transformation.

Typical cart dynamic acceleration measurements are shown in Figures 7A through 7D. The acceleration response is measured in units of gravity $(\mathrm{g}), 1 \mathrm{~g}=\sim 32 \mathrm{ft} / \mathrm{sec}^{2}$. The measurements in Figures 7A-7B were collected at the beginning of the test program for the first set of samples. The measurements in Figures 7C-7D were collected in the middle of the test program for the second set of samples. "Inst Time" in Figures 7A and 7C is a 2 second interval of the recorded acceleration response for the accelerometer locations. The "Power Spectrum" plots in the figures show the acceleration maximum measured for each frequency in the 0-200 Hertz range.

The "Avg=\#" in each spectrum plot indicates the number of two second intervals collected to obtain the displayed data. Comparison of Figure 7A with $7 \mathrm{C}$ is not performed, because of the transient nature of the time data. However, comparison of the spectral data in Figures 7B and 7D should, and does, show close correlation based on elimination of most transient aspects of the data by conversion to the frequency domain and averaging. Examination of the power spectra, recorded at the two different times in the test program, shows minimal variation over the 9 month duration of testing. Spectra from both dates have approximately the same spectral shape, and a similar broadband input magnitude of $\sim 0.1-0.2 \mathrm{~g}$ at the cart floor and on the top of the plastic enclosure.
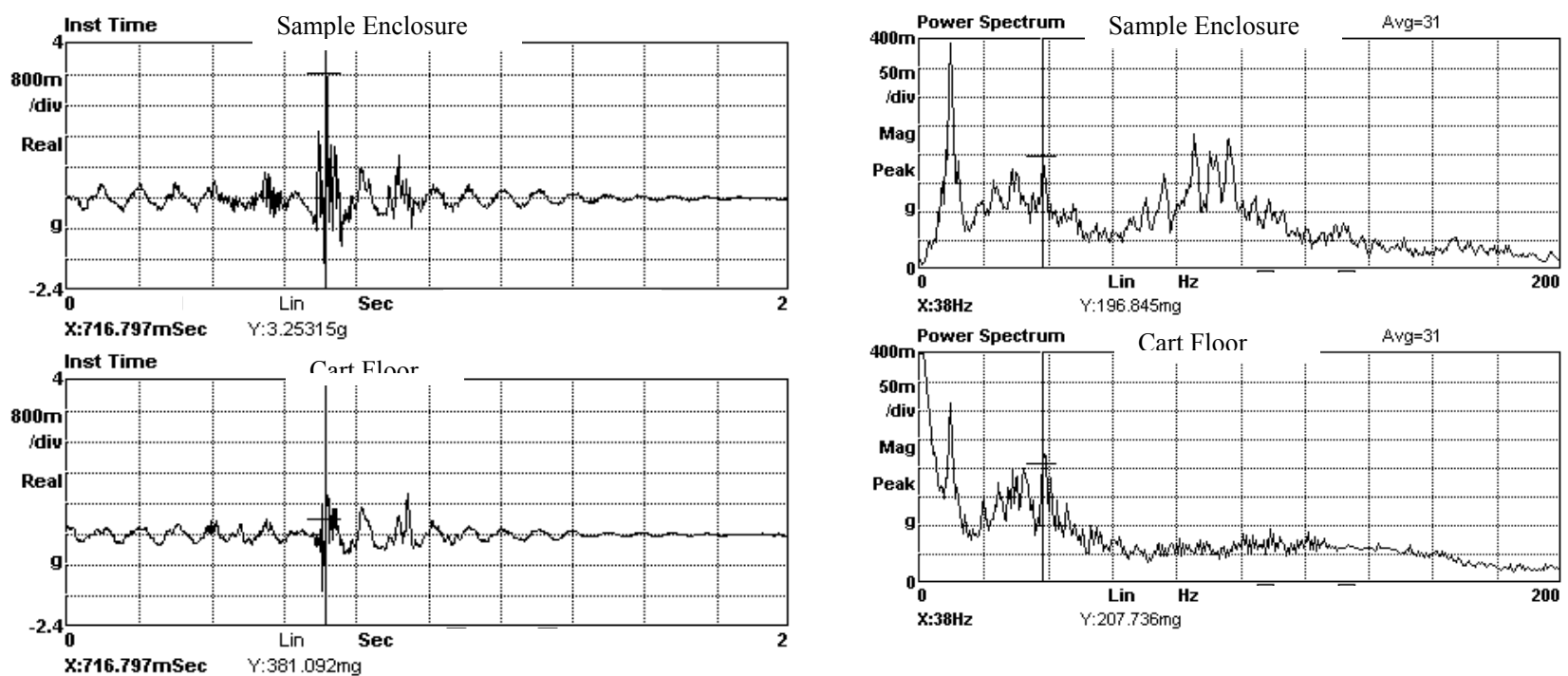

Figure 7A. Two second interval of acceleration response recorded 6/16/2010.

Figure 7B. Spectral Acceleration maxima measured for 31 two second intervals. Recorded 6/16/2010 

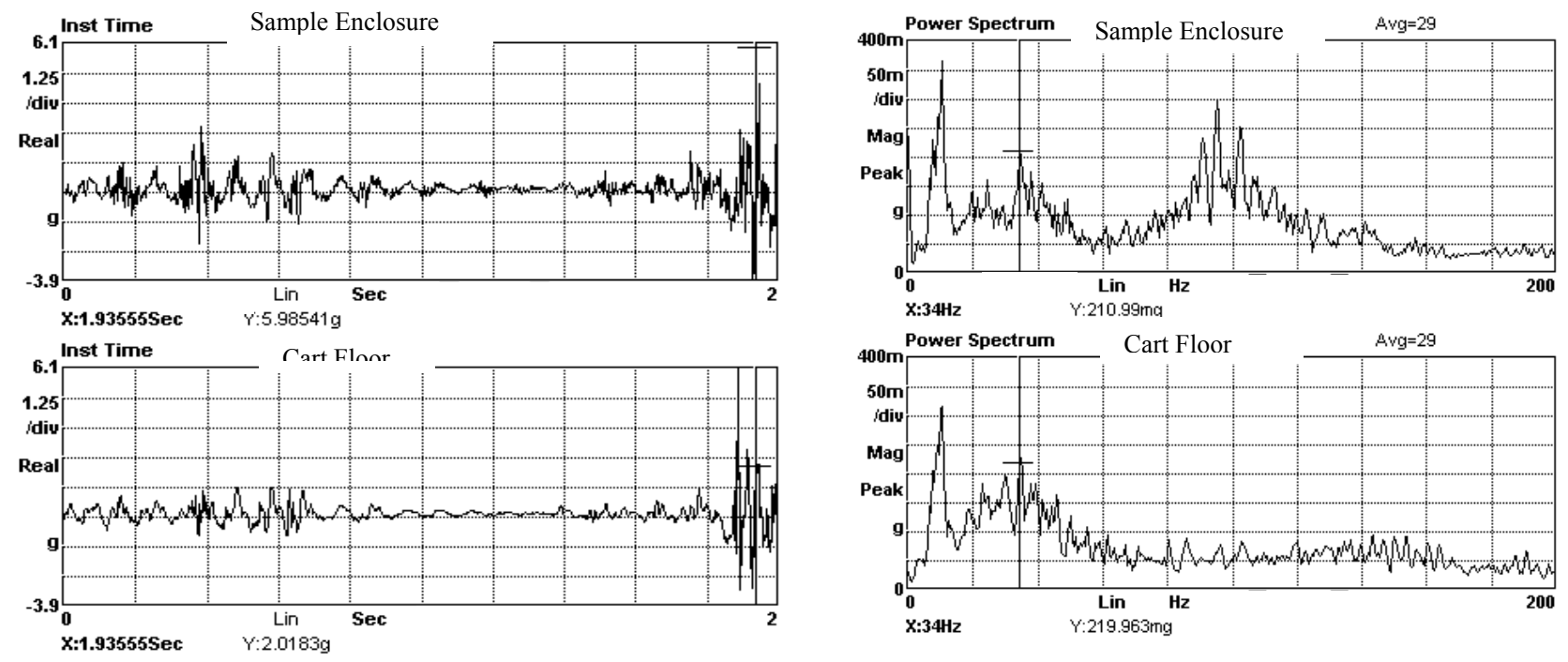

Figure 7C. Two second interval of acceleration response recorded 4/13/2011.

Figure 7D. Spectral Acceleration maxima measured for 29 two second intervals. Recorded 4/13/2011

Figure 7E contains an overlay of the background acceleration power spectrum measurements from the 6/16/2010 and 4/13/2011 test dates. For each background measurement, the cart was stationary, and the only input to the cart was due to vibration transmission from the building floor into the cart's wheels. Based on the $\sim 0.003 \mathrm{~g}$ peak value, it is obvious that the background acceleration level is insignificant when compared to the Figure 7B 0.1-0.2 g magnitude.

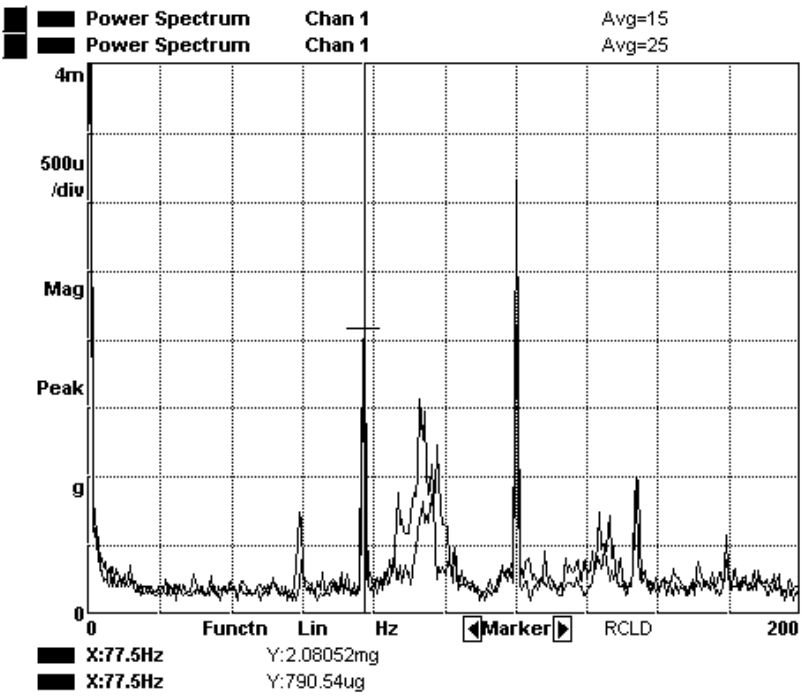

Figure 7E. Floor Input Acceleration data

for tests on $6 / 16 / 2010$ and $4 / 13 / 2011$ 


\section{DISCUSSION}

In the short-term tests (see Figure 4), the initial loading cycle (2.7 or 3.4 psi) is indicative of the response of the lower layers of the fiberboard assembly when the package is first assembled. Similarly, the second loading cycle (5.4 or 6.8) might approximate the response during some period of handling or transport. The removal of the higher load represents an end to the dynamic activity as the package sits in storage.

Under conditions typical of many packages ( 10\%WME, 3.4 psi stress) both the short term and the initial (up to 5 weeks) dynamic samples show about $2 \%$ strain (reduction in height/original height). Under a static stress of 6.8 psi (essentially a single cycle $1 \mathrm{~g}$ load input), the short term sample experienced additional strain of $\sim 2 \%$. Under dynamic loading, the strain also increased an additional $2 \%$ over the following 15 weeks. Although both samples reached approximately the same final strain, the dynamic samples approached this value much more slowly because of the lower magnitude of dynamic loading $(\sim 0.1 \mathrm{~g}$ for the dynamic sample, $\sim 1 \mathrm{~g}$ for the short term sample). In comparison to these results, the compression test sample experienced less strain at $3.4 \mathrm{psi}(\sim 0.7 \%)$ and at $6.8 \mathrm{psi}(1.4 \%)$. This likely results from the immediate measurement of sample displacement during the compression test rather than allowing the sample to settle for a short period before measuring the height.

Compression test data obtained previously indicates a degree of variation in behavior between different packages. This is consistent with observation of other fiberboard properties [5, 7]. Similar variation would be expected in the response to dynamic loading. The degree of compression predicted by the compression test data for a given stress is less than that measured in the dynamic and short term samples. Therefore, the data obtained in dynamic and short term testing are more conservative than compression test data. Accordingly, no further compression testing will be performed under this task.

At elevated moisture levels $(\geq 20 \% \mathrm{WME})$, the behavior varies somewhat. The strains are higher with the increased moisture level, and strain continues to increase for a longer period of time. This behavior is seen in all samples - dynamic, control (static), and short term. However, the rate of compression of the dynamic sample while between dynamic cycles is less than the rate of compression of the control (static) sample. As each of the short term samples is unloaded, there is some recovery of sample height, but some compression remains.

In the dynamic samples, the degree of compression observed to date in the second set of samples is not entirely consistent with that for the first set. The $25 \% \mathrm{WME}$ dynamic sample has compacted at about the same rate as the $20 \% \mathrm{WME}$ sample, and the $35 \% \mathrm{WME}$ dynamic sample has compacted at a slower rate than the 20,25, and $30 \% \mathrm{WME}$ samples. The $35 \% \mathrm{WME}$ static sample has compacted slightly less than the $30 \% \mathrm{WME}$ sample (see Figure 6). Testing of the second set is continuing to identify if this behavior persists.

In general, higher fiberboard moisture content corresponds to higher total compaction, a greater rate of compaction, and continued compaction over a longer period of time. These trends have been noted previously [6]. Superimposed on these trends, as moisture levels fluctuate, the sample height tends to fluctuate in unison, as illustrated in Figure 8. This correlation with moisture fluctuation was stronger for moisture levels from $6 \% \mathrm{WME}$ to $30 \% \mathrm{WME}$. 

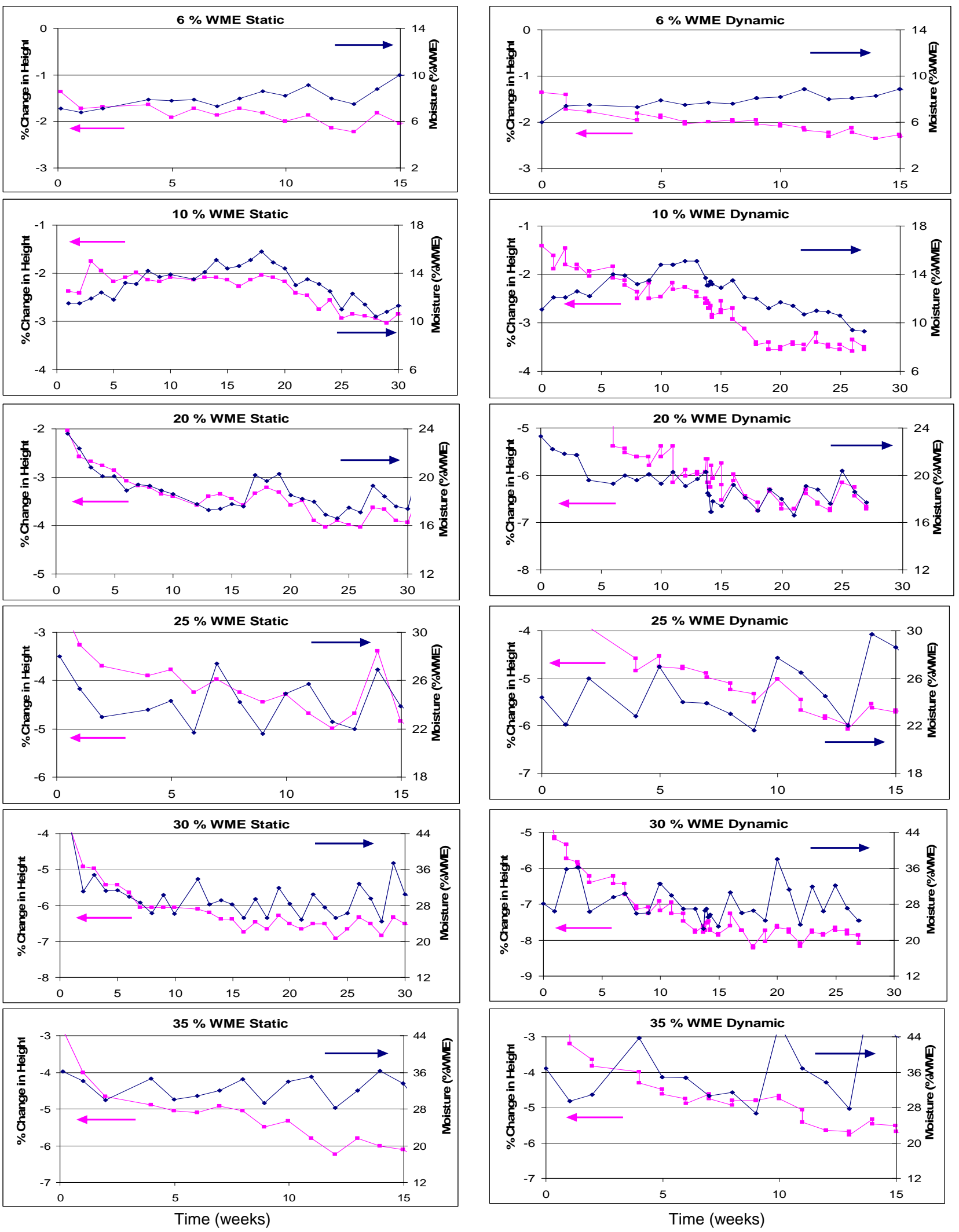

Figure 8. Typical correlation between moisture content and compression behavior, shown for 6 , 10, 20, 25, 30 and $35 \%$ WME static (control) and dynamic samples. 
The safety analysis for the 9975 package includes discussion of the vibration from road transportation loadings [8]. The vibration levels are bounded by a high amplitude low frequency envelope of $1-1.5 \mathrm{~g}$ at $2-7 \mathrm{~Hz}$, and a power spectral density value of $0.001 \mathrm{~g}^{2} / \mathrm{Hz}$ in the frequency range from 10-40 Hz. The low frequency high acceleration input would not result in significant packaging response due to the higher resonant frequencies indicated in packaging qualification calculations. However, input over the $10-40 \mathrm{~Hz}$ range would result in significant package response, as this is where the fundamental frequency of the system occurs, and as such defines the input envelope and a conservative bound to typical vibrations experienced on a smooth road. Similar loadings might be postulated to result from handling packages within a facility.

The measured displacement data for the first sample set (Sample IDs 50C, 40E, 40F), and the data obtained in the first 2 weeks for the second sample set (Sample IDs D-50-6, D-40-25, D-4035) are included in Table 3. Measurements for the first sample set are complete, and data are still being recorded for the second sample set.

Table 3. Measured Response Data

\begin{tabular}{|l|r|c|c|c|c|c|}
\hline $\begin{array}{c}\text { Sample } \\
\text { ID }\end{array}$ & $\begin{array}{c}\text { Nominal } \\
\text { Moisture } \\
\text { Content } \\
\text { \%WME }\end{array}$ & $\begin{array}{c}\text { IA] } \\
\text { Initial Sample } \\
\text { Height w/o } \\
\text { weight (in) }\end{array}$ & $\begin{array}{c}{[\mathrm{B}]} \\
\text { Initial } \\
\text { Height with } \\
\text { weight (in) }\end{array}$ & $\begin{array}{c}{[\mathrm{W}]} \\
\text { Weight } \\
\text { Added } \\
\text { (Lb) }\end{array}$ & $\begin{array}{c}{[\mathrm{D}]} \\
\text { Final } \\
\text { Height with } \\
\text { Weight (in) }\end{array}$ & $\begin{array}{c}{[\mathrm{E}]} \\
\text { Final Height } \\
\text { w/o Weight } \\
\text { (in) }\end{array}$ \\
\hline 50C & 10 & 2.116 & 2.095 & 50.6 & 2.041 & 2.07 \\
\hline $40 \mathrm{E}$ & 20 & 2.192 & 2.166 & 40.7 & 2.045 & 2.069 \\
\hline 40F & 30 & 2.300 & 2.262 & 40.5 & 2.114 & 2.139 \\
\hline D-50-6 & 6 & 2.208 & 2.191 & 50.6 & 2.165 & $*$ \\
\hline D-40-25 & 25 & 2.292 & 2.270 & 40.7 & 2.178 & $*$ \\
\hline D-40-35 & 35 & 2.278 & 2.252 & 40.5 & 2.145 & $*$ \\
\hline
\end{tabular}

*Test In-Progress

In the context of this study, important sample dynamic parameters include stiffness, damping, and natural frequency. The Transport Acceleration Response (TAR), defined here as the vibration input level design requirement associated with the specific mode of transport, is a function of these sample dynamic parameters. The TAR value is used for comparison to test input to assess how well the tests simulate package road induced response. Using the data in Table 3, it is possible to calculate stiffness, natural frequency, and TAR for each individual sample. Results for the sample dynamic parameters, obtained using the Table 3 data and the same dynamic analysis methodology implemented for 9975 package qualification, are provided in Table 4. The dynamic system model used for the 9975 closely matches the loaded sample configuration used for these tests where a rigid mass is provided vertical support by fiberboard.

The stiffness of the container inside the 9975 is considered sufficiently high to decouple rigid body response of the content/fiberboard system from the flexible response of the container. For this package system, the fundamental resonant frequency was calculated as $\sim 22 \mathrm{~Hz}$ in the 9975 evaluation. The TAR, corresponding to this frequency and a damping value of 0.1 , which is less than published dry fiberboard damping values [9], was determined to be $0.42 \mathrm{~g}$. In comparison to the dynamic testing acceleration input shown in Figures 7B and 7D, the 0.1-0.2 g input is 25$50 \%$ of the TAR requirement with an assumed fiberboard damping value of 0.1 . The cumulative duration of dynamic excitation for sample set 1 was approximately 1 hour over 6 months. There 
is not a TAR exposure duration design requirement available that can be compared to the duration of dynamic testing. The approximate 1 hour of sample dynamic input included continuous shock input, which is analogous to subjecting a package to one hour of continuous travel on a very rough or hole riddled road. The shock input, typical during testing, is indicated by the high amplitude short duration acceleration values in Figures 7A and 7C.

In regard to fiberboard damping, the exact value of damping has not been determined experimentally. Since a value of 0.1 was used in the packaging design calculations, 0.1 is also used here, for all samples regardless of moisture content, to calculate the TAR. It should be noted that the value calculated for the TAR decreases with increasing damping level, and results in closer agreement between TAR and the applied dynamic test input. Impulse/Response testing is planned to determine the damping level associated with each dynamic sample in the second set $(6,25$, and $35 \% \mathrm{WME})$, for comparison to the 0.1 damping value used in the TAR calculations.

The sample dynamic parameter results listed in Table 4 were obtained using the following equations:

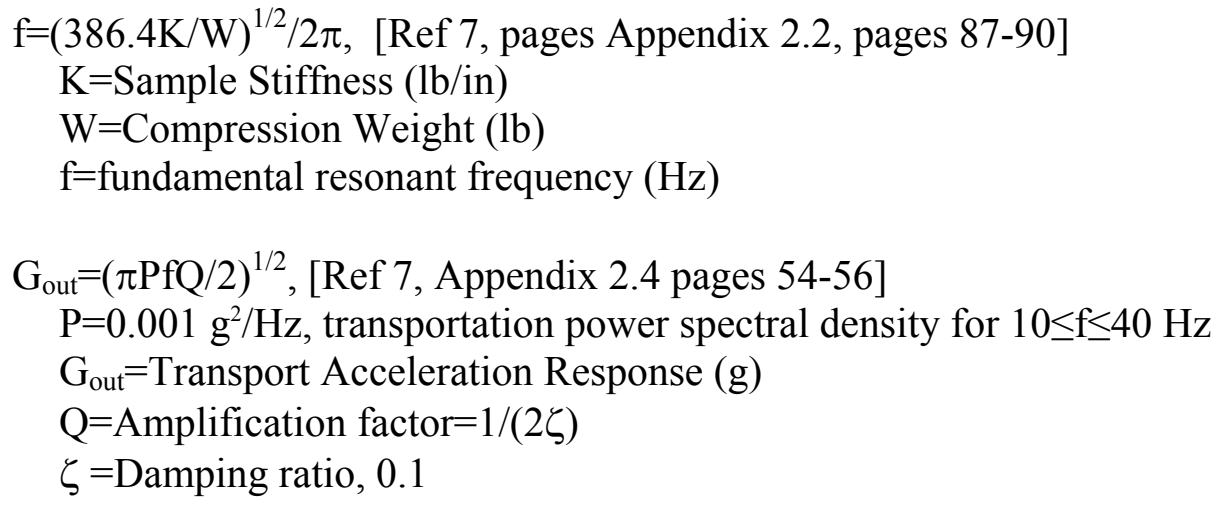

Examination of the Table 4 data results in several noteworthy observations. Although natural frequency is a function of stiffness, the natural frequency results do not vary as much as the stiffness. The calculated range of natural frequency values $(16-24 \mathrm{~Hz})$ is in good agreement with the package documented value of $22 \mathrm{~Hz}$ from the SARP [8]. All samples experienced permanent compression (Column $[\mathrm{F}]$ ) with values increasing proportional to the moisture level. For the 30 $\%$ WME sample, the initial compression caused by weight addition was not recovered when the weight was removed, as indicated by comparison of the initial sample compression (Column [C]) and the sample elastic rebound (Column [G]). This is indicative of an overall change in sample stiffness during the dynamic test period. The other samples from set 1 fully recovered initial compression despite experiencing some permanent compression. All tests show changes in total sample compression (Column [H]), sample compression after the weight was added (Column $[\mathrm{I}]$ ), and permanent deformation that occurred during the dynamic test sequence (Column $[\mathrm{J}]$ ) respectively. The data for each of these quantities show a trend of increasing value with an increase in moisture level.

The stiffness and fundamental resonant frequency are calculated for both sets of dynamic samples in Table 4. Note that both of these parameters tend to decrease as the moisture level increases. The two exceptions to this trend are seen with the 25 and $35 \% \mathrm{WME}$ samples in the 
second set. In both of these samples, each parameter has a higher value than would be expected based on the trend displayed by the other samples. It is noted that these two samples also deviated from the overall trend in the rate and amount of compression. A cause of this deviation has not yet been identified, but it is noted that fiberboard is inherently heterogeneous, and variation in properties should be expected.

Table 4: Calculated Dynamic Response Data

\begin{tabular}{|c|c|c|c|c|c|c|c|c|c|c|}
\hline $\begin{array}{c}\text { Sample } \\
\text { ID }\end{array}$ & $\begin{array}{l}\text { Nominal } \\
\text { Moisture } \\
\text { Content } \\
\% \mathrm{WME}\end{array}$ & $\begin{array}{c}{[\mathrm{C}]=\mathrm{A}-\mathrm{B} \text { Initial }} \\
\text { Sample } \\
\text { Compression } \\
\text { (in) }\end{array}$ & $\begin{array}{c}{[\mathrm{F}]=\mathrm{A}-\mathrm{E}} \\
\text { Permanent } \\
\text { Compression } \\
\text { (in) }\end{array}$ & $\begin{array}{l}{[\mathrm{G}]=\mathrm{E}-\mathrm{D}} \\
\text { Sample } \\
\text { Elastic } \\
\text { Rebound } \\
\text { (in) }\end{array}$ & $\begin{array}{c}{[\mathrm{H}]=\mathrm{A}-\mathrm{D}} \\
\text { Total } \\
\text { Compression } \\
\text { with Weight } \\
\text { (in) }\end{array}$ & $\begin{array}{c}[\mathrm{I}]=\mathrm{B}-\mathrm{D}] \\
\text { Sample } \\
\text { Deformation } \\
\text { Post Weight } \\
\text { Addition } \\
\text { (in) }\end{array}$ & $\begin{array}{c}{[\mathrm{J}]=\mathrm{B}-\mathrm{E}} \\
\text { Permanent } \\
\text { Deformation } \\
\text { after initial } \\
\text { compression } \\
\text { (in) }\end{array}$ & $\begin{array}{l}{[\mathrm{K}]=\mathrm{W} / \mathrm{C}} \\
\text { Stiffness } \\
\mathrm{K} \text { (lb/in) }\end{array}$ & $\begin{array}{c}\text { Fundamental } \\
\text { Resonant } \\
\text { Frequency } \\
\mathrm{f}(\mathrm{Hz})\end{array}$ & $\begin{array}{c}\text { Transport } \\
\text { Acceleration } \\
\text { Response } \\
\text { TAR }(\mathrm{g})\end{array}$ \\
\hline $50 \mathrm{C}$ & 10 & 0.021 & 0.046 & 0.029 & 0.075 & 0.054 & 0.025 & 2410 & 21.59 & 0.41 \\
\hline $40 \mathrm{E}$ & 20 & 0.026 & 0.123 & 0.024 & 0.147 & 0.121 & 0.097 & 1565 & 19.40 & 0.39 \\
\hline $40 \mathrm{~F}$ & 30 & 0.038 & 0.161 & 0.025 & 0.186 & 0.148 & 0.123 & 1066 & 16.05 & 0.36 \\
\hline D-50-6 & 6 & 0.017 & * & * & 0.043 & $*$ & $*$ & 2976 & 23.99 & 0.43 \\
\hline D-40-25 & 25 & 0.022 & $*$ & $*$ & 0.114 & $*$ & $*$ & 1850 & 21.09 & 0.41 \\
\hline D-40-35 & 35 & 0.026 & $*$ & $*$ & 0.133 & $*$ & $*$ & 1558 & 19.40 & 0.39 \\
\hline
\end{tabular}

* Test in Progress

The effects of the dimensional changes on package dynamics can be postulated based on the Table 4 results. Since the overall height of the fiberboard samples decreased, the fiberboard experienced "sag" due to either slow creep under the constant static load, or slow creep with possible additional sag contribution from the dynamic excitation. It is likely that the overall shock absorption capability of the reduced fiberboard column also decreased. However, the initial shock absorption capability of the fiberboard was excessive in regard to demand, and the reduction due to sagging of the fiberboard is likely small.

For samples $40 \mathrm{E}$ and $50 \mathrm{C}$, the initial deformation due to weight addition is approximately equal to the sample rebound. This result indicates that the sample stiffness was unchanged at the end of the 6 month test period. In contrast, sample 40F did not recover a substantial amount of the initial compression. This indicates that the overall stiffness of $40 \mathrm{~F}$ has increased to approximately that of 40E, based on nearly identical rebound values in column [G]. Since the variation in stiffness and natural frequency for all of the samples only results in a difference of $\sim 0.05 \mathrm{~g}$ for the TAR, the change in fiberboard stiffness would have a minimal affect on the dynamic behavior of the 9975 package/container system. However, given a substantial increase in the fiberboard stiffness, due to greater sagging, it is possible that natural frequency increases coupled with a reduction in damping could result in higher loads experienced by package contents. Once again, the margin between capacity and demand related to vibration loading is great, and a limited amount of sagging should not produce unacceptable response. Based on the test data presented, a 5\% reduction in sample 40F height was measured, and limiting package post loading deformation to a similar value would likely provide a conservative bound for maintaining acceptable package dynamic response.

Examination of Figures 7A through 7D shows higher acceleration values in both "Inst Time" and "Power Spectrum" plots for the accelerometer mounted on the sample enclosure. This result is expected as the hard steel and plastic enclosure has additional flexibility which amplifies the 
base input. Since multiple sample enclosures are placed on the cart for dynamic loading, the dynamic acceleration imparted to each sample from the cart floor would be slightly different, but bounded by the "Sample Enclosure" and "Cart Floor" data.

The power spectrum for "Cart Floor" in Figure 7D is considered typical for sample dynamic loading. The spectrum indicates a fairly uniform acceleration input of 0.1-0.2 $\mathrm{g}$ in the 5-200 Hertz frequency range. Excitation in the 0-5 Hertz range is low, as expected, due to the hardness of the cart wheels, and steel expanded metal surface. The hard surfaces of contact result in a broad frequency range of input, as opposed to a smaller range of low frequency input if the duration of impact were increased by using softer material for the cart wheels. Since the mass mounted on the top of each sample is rigid, the dynamic force experienced by a sample would be equivalent to the input acceleration multiplied by the weight of the compressing object, applied as a sinusoidal load over a duration equal to time spent rolling the cart over the rough surface. Additionally, the peak static equivalent dynamic shock load can be approximated by multiplication of the compressive weight by the peak acceleration value shown in either Figure 7A $(>3 \mathrm{~g})$ or $7 \mathrm{C}(\sim 6 \mathrm{~g})$. This is a very short duration acceleration, and as such, mechanical response or stress assessment would need to take into account time dependent properties for shock effect evaluation.

\section{CONCLUSIONS}

Moisture levels and dynamic loading contribute to the compaction of the fiberboard. For a given moisture level, dynamic loadings on the fiberboard will lead to greater compaction than static loading. Beyond a certain degree of compaction, continued dynamic loading causes little additional compaction. Rather, subsequent change in fiberboard height is driven more by variation in moisture content.

The exposure of the samples to dynamic excitation indicates a general trend of greater compaction for higher moisture levels. There appears to be a threshold moisture level where fiberboard initial compression becomes unrecoverable. Below this threshold, the fiberboard would show no change in dynamic response, but may have slightly reduced shock absorption capabilities. Negative transportation effects due to fiberboard "sag" may be avoided by inservice inspection of the fiberboard height reduction with time. The current practice of verifying that the axial gap at the top of the package is less than 1 inch provides confidence against excessive reduction of fiberboard height. Above the threshold moisture value, the fiberboard stiffness increases, but based on an increase in the fundamental resonant frequency, the net effect may result in either slightly higher or even significantly lower transportation dynamic loading depending on the final stiffness. The shock absorption capability of the higher moisture exposure would result in reduced shock absorption capability based on higher fiberboard stiffness, and the related reduced fiberboard height. While higher moisture would likely result in greater damping, the fiberboard damping level as a function of moisture level is unknown, but would greatly influence the dynamic response of the package. Additional tests to determine damping level are warranted to fully characterize dynamic response of the fiberboard and packaging. 


\section{REFERENCES}

[1] SRNL-TR-2010-00044, “Task Technical and Quality Assurance Plan for Testing of Moisture Effects on Model 9975 Package (U)”, Rev 0, March 2010.

[2] WSRC-TR-2001-00286, "SRS Surveillance Program for Storage of Pu Material in KAMS", Rev 4, July 2008.

[3] PVP2010-25087, "Effects of Moisture in the 9975 Shipping Package Fiberboard Assembly", W. L. Daugherty. K. A. Dunn, J. L. Murphy and E. R. Hackney, Proceedings of PVP2010, ASME Pressure Vessels \& Piping Division Conference, July 18-22, 2010, Bellevue, WA.

[4] PVP2010-25118, "Aging Model for Cane Fiberboard Overpack in the 9975 Shipping Package", W. L. Daugherty and S. P. Harris Jr, Proceedings of PVP2010, ASME Pressure Vessels \& Piping Division Conference, July 18-22, 2010, Bellevue, WA.

[5] PVP2007-26114, "Properties of Fiberboard Overpack Material in the 9975 Shipping Package Following Thermal Aging”, W. L. Daugherty, Proceedings of PVP2007, ASME Pressure Vessels \& Piping Division Conference, July 22-26, 2007, San Antonio, TX.

[6] "Compaction of Fiberboard Overpack Materials in a 9975 Shipping Package" T. M. Stefek, W. L. Daugherty, E. G. Estochen, J. L. Murphy, Proceedings of INMM Institute of Nuclear Materials Management 51st Annual Meeting, July 11-15, 2010, Baltimore, MD.

[7] PVP2005-71568, "Mechanical Properties of Fiberboard Overpack materials in the 9975 Shipping Package", W. L. Daugherty and P. R. Vormelker, Proceedings of PVP2005, ASME Pressure Vessels \& Piping Division Conference, July 17-21, 2005, Denver, CO

[8] S-SARP-G-00003, "Safety Analysis Report for Packaging Model 9975”, Revision 0, Appendix 2.2, January 2008.

[9] Report No. WMEL-2002-03, Monotonic and Cyclic Tests of Shear Walls with Gypsum Wallboard, Fiberboard, and Hardboard Sheathing, Wood Materials and Engineering Laboratory, Washington State University, J.D. Dolan. 
CC: J. S. Bellamy, 773-41A

G. T. Chandler, 773-A

W. L. Daugherty, 773-A

K. A. Dunn, 773-41A

E. G. Estochen, 773-A

E. R. Hackney, 705-K

M. K. Hackney, 705-K

N. C. Iyer, 773-41A

D. R. Leduc, 773-41A

J. W. McClard, 703-H

J. W. McEvoy, 707-42B

T. M. Monahon, 705-K

J. L. Murphy, 773-41A

T. M. Stefek, 773-41A

Document Control 